\title{
Acellular dermal matrices in immediate breast reconstruction: a literature review
}

\author{
Mohammed Attallah Alharbi ${ }^{1 *}$, Fahad K. Aljindan', Reshan Mane Al Reshan', \\ Khalid Dakhelallah Almutairi ${ }^{3}$, Fatimah Mofeed Almosabh ${ }^{4}$, Moayad Abdullah Zarbh ${ }^{5}$, \\ Renad Adel Bahadi ${ }^{6}$, Abdullah Mohammed Abutaleb ${ }^{5}$, Majid Ghazi AlNufaie ${ }^{7}$, \\ Asma Abdulrahman Alhrthialsharif ${ }^{6}$, Ghadh Abdulmuhaymin Bukhary ${ }^{6}$, \\ Asmaa Mahfouz Al-hamdi ${ }^{6}$
}

\author{
${ }^{1}$ Department of Plastic Surgery, King Abdullah Medical City, Mecca, Saudi Arabia \\ ${ }^{2}$ Department of Radiology, King Khalid Hospital, Najran, Saudi Arabia \\ ${ }^{3}$ Department of General Surgery, King Khalid Hospital, Almajmah, Saudi Arabia \\ ${ }^{4}$ College of Medicine, Medical University of Warsaw, Warsaw, Poland \\ ${ }^{5}$ College of Medicine, King Khalid University, Abha, Saudi Arabia \\ ${ }^{6}$ College of Medicine, Umm Al-Qura University, Mecca, Saudi Arabia \\ ${ }^{7}$ College of Medicine, Taif University, Taif, Saudi Arabia
}

Received: 19 December 2020

Accepted: 05 January 2021

\section{*Correspondence:}

Dr. Mohammed Attallah Alharbi,

E-mail: dr_lugmani@hotmail.com

Copyright: (c) the author(s), publisher and licensee Medip Academy. This is an open-access article distributed under the terms of the Creative Commons Attribution Non-Commercial License, which permits unrestricted non-commercial use, distribution, and reproduction in any medium, provided the original work is properly cited.

\section{ABSTRACT}

There has been an increase in invasive breast carcinoma which many times end up with a mastectomy. The psychological effects of mastectomy can be overwhelming, urging the need for optimum breast reconstruction procedures. Acellular dermal matrices are widely used nowadays due to their favorable outcomes with a few complications. In this study, we review the literature to explore the different types used, cons, and pros of this procedure. Databases like PubMed, Medline, Web of science, Embase, Google scholar, and Scopus were used and searched for following terms "implant-based reconstruction" or "breast reconstruction" or "acellular dermal matrix". All studies that discuss the use of acellular dermal matrices for breast reconstructive surgery were included. Acellular dermal matrices may allow a relatively easy, affordable and time-efficient breast reconstructive surgery. They are associated with less incidence of infection and capsular contracture making them an excellent fit for most procedures. However, $m$ ore studies are needed to help understand possible risk factors, and complications and how to avoid them.

Keywords: Acellular dermal matrices, Breast carcinoma, reconstructive surgery

\section{INTRODUCTION}

The use of breast reconstructive surgery has increased in the last few years due to an increase in the incidence of invasive breast carcinoma. ${ }^{1,2}$ It was estimated that there are 252,710 newly diagnosed invasive breast carcinoma cases per year. The most widely used approach to radically excise the cancer is mastectomy. It is estimated that $70 \%$ of patients undergo breast reconstruction surgery. ${ }^{1,2}$

The traditional method for reconstruction is two-stage implant-based breast reconstruction which initially places a tissue expander under pectoralis major muscle. ${ }^{1,3,4}$ 
However, this classic method is limited by the long duration for expansion and its associated pain. Furthermore, this approach does not allow for inferolateral and lower pole expansion urging the need for a more suitable approach. That is why acellular dermal matrices became widely used since they permit a shorter for expansion. ${ }^{1}$

Acellular dermal matrices (ADMs) are a processed tissue grafts which are synthesized from cadaveric tissues or animal skin. ${ }^{5}$ They are mainly composed of tissue matrix with all the cells removed so the remaining part become the supporting matrix in the form of cellular matrix, the basement membrane and collagen fibers. The removal of cellular components is important as it decreases the risk of rejection and infection. ${ }^{4-6}$ ADMs act as a biological support system to help in forming new tissue growth, cellular growth and vascularization. Current study, is a review of literature to discuss the different indications and contraindications of ADMs compared to other approaches.

\section{SEARCH STRATEGY}

A systematic search was conducted to identify relevant studies in the following databases: PubMed, Medline, Web of science, Embase, Google scholar, and Scopus were used and searched for following terms "implantbased reconstruction" or "breast reconstruction" or "acellular dermal matrix". The reference lists were manually searched to identify additional relevant studies meeting inclusion criteria. All studies that discuss the use of acellular dermal matrices in breast reconstructive surgery were included.

Eleven reported acellular dermal matrices used in breast reconstructive surgery were identified. ${ }^{7}$ Each of these has its characteristics and preoperative preparation. These include : AlloDerm, AlloMax (Neoform), Derm Acell, Derma Matrix, Flex HD, Permacol, Strattice, SurgiMend PRS, and Veritas (Table 1).

Table 1: The most used acellular dermal matrix.

\begin{tabular}{|llllll|}
\hline Manufacturer & Source & Sterility & Orientation & Shelf life & Key considerations \\
\hline Allergan & Human & Yes & Yes & 2 years & Short preparation time \\
\hline Allergan & Human & No & Yes & 2 years & -- \\
\hline Bard/Davol & Human & Yes & No & 5 years & Short preparation time and long half life \\
\hline Stryker & Human & No & Yes & 2 years & Cost is high \\
\hline MTF/Synthes & Human & No & Yes & 3 years & $\begin{array}{l}\text { Short preparation time, multiple } \\
\text { thicknesses }\end{array}$ \\
\hline MTF/Synthes & Human & No & Yes & 3 years & Cost is high \\
\hline Medtronic & Porcine & Yes & No & 3 years & Nonhuman \\
\hline Allergan & Purified silk & Yes & No & 3 years & Short preparation time \\
\hline Allergan & Porcine & Yes & No & 18 months & Short preparation time and short half life \\
\hline Integra & Fetal bovine & Yes & No & 3 years & Short preparation time \\
\hline Baxter & $\begin{array}{l}\text { Fetal bovine } \\
\text { pericardium }\end{array}$ & Yes & No & 3 years & Short preparation time \\
\hline Ethicon & $\begin{array}{l}\text { Synthetic } \\
\text { (polyglactin 910) }\end{array}$ & Yes & No & -- & Short preparation time \\
\hline
\end{tabular}

Most of these are of a human source of dermal matrices except for Permacol, Seri Scaffold, Strattice and SurgiMend PRS, and Vertas. ${ }^{7}$ AlloDerm is considered the most popular ADMs due to the massive research that supports its favorable outcomes and because of its relatively easy preparation. ${ }^{7}$ When compared to other acellular dermal matrices, Alloderm has shown to allow better vascularization, fibroblast infiltration, and rapid tissue repair. The choice from different ADMs is mainly dependent on the surgeons' experience and preference. 7 Nevertheless, the following should be taken into consideration when determining the appropriate type of ADM: the source of the graft, whether bovine or not, the treatment used to prepare the graft, sterilization conditions and shelf life. During surgery, the surgeon has to consider the preparation time required, the proper orientation and substrate polarity during grafting.?

\section{ADVANTAGES OF ACELLULAR DERMAL MATRICES}

ADMs lower the incidence of postoperative capsular contracture rate and are considered stable for the subsequent two years of surgery. ${ }^{8}$ The lower capsular contracture incidence is mainly caused by the reduced inflammatory conditions associated with their use. Orenstein SB et al. reported that AlloDerm decreased the production of interleukins 1B, IL-6, and vascular endothelial growth. ${ }^{9}$ In addition, the healing process was associated with less fibrosis. These less inflammatory conditions maybe attributed to decreased musculofascial dissection associated with the use of ADMs. ${ }^{10}$ In addition, the use of ADMs may reduce the need for larger implants and fills needed to optimize the final volume and contour of the breast. ${ }^{11,12}$ Another main advantage of the acellular dermal matrices is the rapid return to normal appearance 
of the reconstructed breast which can associated with better outcomes due to a better psychological effect. ${ }^{13}$

\section{COMPLICATIONS OF ACELLULAR DERMAL MATRICES}

There is conflicting evidence regarding the complications of acellular dermal matrices. A study found that the use of acellular dermal matrices had an increased incidence of complications such as hematoma/seroma formation, and infections. ${ }^{14}$ In the above mentioned study seroma formation was reported to be as high as $14.1 \%$ in patients with ADM compared to only $2.7 \%$ in patients who did not use acellular dermal matrices. ${ }^{15}$ The rates of infections were also $8.9 \%$ in patients who had acellular dermal matrices compared to $2.1 \%$ in patients without ADM. However, another study found that only $1.5 \%$ of cases developed seroma and 3\% of cases got an infection after a single-stage implant with acellular dermal matrix. ${ }^{12}$ Liu et al found a significant difference $(p=$ $0.031)$ in the incidence of infection rate when acellular dermal matrices were used (estimated to be $6.8 \%$ ) when compared to the control group (estimated to be $2.5 \%$ ). ${ }^{16}$

More studies investigated other risk factors for ADMs complications and found that obesity was the highest risk factor with acellular dermal matrices use. ${ }^{17,18}$ Furthermore, obesity was mainly associated with seroma, infection and mastectomy skin flap necrosis. These complications were highly associated with obesity, especially with the use of bovine ADMs. ${ }^{17,18}$ Interestingly, another study on obesity compared the outcomes of ADMs use to traditional submuscular techniques and reported less incidence of infection, seroma, and mastectomy flap necrosis as well as less risk of implant and malposition and contractures. ${ }^{19}$

\section{FACTORS AFFECTING THE CHOICE OF THE APPROPRIATE TYPE OF ACELLULAR DERMAL MATRICES}

One of the most important factors that affect surgeons' choice of ADMs is the cost. Permacol is considered to be one of the cheapest acellular dermal matrices as it costs around $21.63 \$$ per $\mathrm{cm}^{2}$ while the most expensive is DermAcell at $34 \$$ per $\mathrm{cm}^{2} .^{20}$ Meanwhile, other expereimental acellular dermal matrices (not approved for use) prices range from $20 \$$ to $35 \$$ per $\mathrm{cm}^{2} .{ }^{20}$ One study claimed that ADMs may not be necessary for breast construction and the that reconstructive procedure can be carried out without using them. The same study argues that acellular dermal matrices can be costly and don't actually reduce the incidence of complications.

Other studies suggested polyglactin 910, or vicryl mesh is considered as a cheap alternative to acellular dermal matrices. ${ }^{21}$ A review found it to be safe, cheap, and has a lower complication rate. In addition, these were found to be ten times cheaper than acellular dermal matrices. However, another study found that vicryl mesh was associated with a higher rate of infection in most cases. $^{21,22}$ Other reported factors that can affect the choice of ADMs include body mass index (BMI) of the patient, breast size, and whether the patient received radiation or not. Intraoperative factors can also play an important role in deciding whether acellular dermal matrices can be used; these include lymph node biopsy results, pectoralis width and integrity, and vascularity of the flap. ${ }^{23}$

\section{CONCLUSION}

Acellular dermal matrix is considered a useful tool that is used nowadays for breast reconstructive surgery due to its good outcomes. Despite the possible complications, their benefits can outweigh the risks when compared to other modalities. Lastly, more studies are needed to understand why complications occur and how to avoid them.

Funding: No funding sources

Conflict of interest: None declared

Ethical approval: Not required

\section{REFERENCES}

1. Lennox PA, Bovill ES, Macadam SA. EvidenceBased Medicine: Alloplastic Breast Reconstruction. Plast Reconstr Surg. 2017;140(1):94e-108e.

2. Kummerow KL, Du L, Penson DF, Shyr Y, Hooks MA. Nationwide trends in mastectomy for earlystage breast cancer. JAMA Surg. 2015;150(1):9-16.

3. Salzberg CA. Nonexpansive immediate breast reconstruction using human acellular tissue matrix graft (AlloDerm). Ann Plastic Surg. 2006;57(1):1-5.

4. Spear SL, Parikh PM, Reisin E, Menon NG. Acellular dermis-assisted breast reconstruction. Aesthetic Plast Surg. 2008;32(3):418-25.

5. Bastidas N, Ashjian PJ, Sharma S. Acellular dermal matrix for temporary coverage of exposed critical neurovascular structures in extremity wounds. Ann Plast Surg. 2009;62(4):410-3.

6. Buinewicz B, Rosen B. Acellular cadaveric dermis (AlloDerm): a new alternative for abdominal hernia repair. Ann Plast Surg. 2004;52(2):188-94.

7. Cheng A, Saint-Cyr M. Comparison of different ADM materials in breast surgery. Clin Plast Surg. 2012;39(2):167-75.

8. Salzberg CA, Ashikari AY, Berry C, Hunsicker LM. Acellular dermal matrix-assisted direct-to-implant breast reconstruction and capsular contracture: a 13year experience. Plast Reconstr Surg. 2016;138 (2):329-37.

9. Orenstein SB, Qiao Y, Kaur M, Klueh U, Kreutzer DL, Novitsky YW. Human monocyte activation by biologic and biodegradable meshes in vitro. Surg Endosc. 2010;24(4):805-11.

10. Serrurier LC, Rayne S, Venter M, Benn CA. Directto-implant breast reconstruction without the use of an acellular dermal matrix is cost effective and oncologically safe. Plast Reconstr Surg. 2017;139(4): 809-17. 
11. Mofid MM. Acellular dermal matrix in cosmetic breast procedures and capsular contracture. Aesthet Surg J. 2011;31(7 Suppl):77S-84S.

12. Yu D, Hanna KR, LeGallo RD, Drake DB. Comparison of histological characteristics of acellular dermal matrix capsules to surrounding breast capsules in acellular dermal matrix-assisted breast reconstruction. Ann Plast Surg. 2016;76(5): 485-8.

13. Zhong $\mathrm{T}, \mathrm{Hu} \mathrm{J}$, Bagher $\mathrm{S}$. A comparison of psychological response, body image, sexuality, and quality of life between immediate and delayed autologous tissue breast reconstruction: a prospective long-term outcome study. Plast Reconstr Surg. 2016; 138(4):772-80.

14. Zhao X, Wu X, Dong J, Liu Y, Zheng L, Zhang L. A meta-analysis of postoperative complications of tissue expander/implant breast reconstruction using acellular dermal matrix. Aesthetic Plast Surg. 2015; 39(6):892-901.

15. Vardanian AJ, Clayton JL, Roostaeian J. Comparison of implant-based immediate breast reconstruction with and without acellular dermal matrix. Plast Reconstr Surg. 2011;128(5):403e-10e.

16. Liu AS, Kao H-K, Reish RG, Hergrueter CA, May JW, Guo L. Postoperative complications in prosthesis-based breast reconstruction using acellular dermal matrix. Plast Reconstr Surg. 2011;127(5): 1755-62.

17. Chun YS, Verma K, Rosen H. Implant-based breast reconstruction using acellular dermal matrix and the risk of postoperative complications. Plast Reconstr Surg. 2010;125(2):429-36.

18. Selber JC, Wren JH, Garvey PB. Critical evaluation of risk factors and early complications in 564 consecutive two-stage implant-based breast reconstructions using acellular dermal matrix at a single center. Plast Reconstr Surg. 2015;136(1):1020.

19. Kim JYS, Davila AA, Persing S. A meta-analysis of human acellular dermis and submuscular tissue expander breast reconstruction. Plast Reconstr Surg. 2012;129(1):28-41.

20. Cheng A, Saint-Cyr M. Comparison of different ADM materials in breast surgery. Clin Plast Surg. 2012;39(2):167-75.

21. Rodriguez-Unda N, Leiva S, Cheng HT, Seal SM, Cooney CM, Rosson GD. Low incidence of complications using polyglactin 910 (Vicryl) mesh in breast reconstruction: A systematic review. J Plast Reconstr Aesthet Surg. 2015;68(11):1543-9.

22. Haynes DF, Kreithen JC. Vicryl mesh in expander/implant breast reconstruction: long-term follow-up in 38 patients. Plast Reconstr Surg. 2014; 134(5):892-9.

23. Jordan SW, Khavanin N, Fine NA, Kim JYS. An algorithmic approach for selective acellular dermal matrix use in immediate two-stage breast reconstruction: indications and outcomes. Plast Reconstr Surg. 2014;134(2):178-88.

Cite this article as: Alharbi MA, Aljindan FK Reshan RMA, Almutairi KD, Almosabh FM, Zarbh MA, et al. Acellular dermal matrices in immediate breast reconstruction: a literature review. Int J Community Med Public Health 2021;8:933-6. 